This item was submitted to Loughborough's Research Repository by the author.

Items in Figshare are protected by copyright, with all rights reserved, unless otherwise indicated.

\title{
Calculation of the kinematics of hypoid gears towards developing a method for an equivalent crossed helical gear pair selection for use in tribological experimental evaluations
}

\section{PLEASE CITE THE PUBLISHED VERSION}

https://doi.org/10.1177/1464419317725943

\section{PUBLISHER}

Sage ( IMechE

\section{VERSION}

AM (Accepted Manuscript)

\section{PUBLISHER STATEMENT}

This work is made available according to the conditions of the Creative Commons Attribution-NonCommercialNoDerivatives 4.0 International (CC BY-NC-ND 4.0) licence. Full details of this licence are available at: https://creativecommons.org/licenses/by-nc-nd/4.0/

\section{LICENCE}

CC BY-NC-ND 4.0

\section{REPOSITORY RECORD}

Athanasopoulos, E., C. Salpistis, Mahdi Mohammadpour, A. Mihailidis, Stephanos Theodossiades, and R. Grekoussis. 2019. "Calculation of the Kinematics of Hypoid Gears Towards Developing a Method for an Equivalent Crossed Helical Gear Pair Selection for Use in Tribological Experimental Evaluations". figshare. https://hdl.handle.net/2134/26008. 


\title{
Calculation of the kinematics of hypoid gears towards developing a method for an equivalent crossed helical gear pair selection for use in tribological experimental evaluations
}

E. Athanasopoulos ${ }^{1}$, C. Salpistis ${ }^{1}$, M. Mohammadpour ${ }^{2}$, A. Mihailidis ${ }^{1 *}$, S. Theodossiades ${ }^{2}$, R. Grekoussis ${ }^{\dagger, 1}$

1) Laboratory of Machine Elements and Machine Design, Department of Mechanical Engineering, Engineering Faculty, Aristotle University of Thessaloniki, Greece

2) Wolfson School of Mechanical, Electrical and Manufacturing Engineering, Loughborough University, Loughborough, UK

\begin{abstract}
To experimentally verify power loss and friction for hypoid gears, measurements in a closed power-loop test rig are necessary. However, these are costly and mechanically complex, since they require additional spur gear reducers in the loop.

ISO directives document the use of crossed helical gear pairs as virtual gears for hypoids to calculate the sliding velocity since, the flank geometry at the mean point can be precisely represented. The use of such pairs can be a cost effective and simpler alternative for testing purposes. However, the validity of this analogy regarding contact mechanics and tribology for the full mesh cycle has not been investigated hitherto.

In the current study a new method for calculating the sliding and rolling speed along the full path of contact of a hypoid gear pair is presented. Cutter kinematics are considered, for the accurate definition of the contact bodies. Using TCA, the load distribution on the tooth under quasi-static conditions and the sliding velocity are calculated for comparison purposes. By applying a selection algorithm, a single experimental crossed helical gear pair is chosen aiming to simulate the contact conditions of hypoid gears. Two test scenarios are studied using EHL film thickness equations and friction models for evaluating the power loss. The contact is an elongated ellipse with varying directions of the sliding and sum velocities, which are considered in the model. The kinematic equivalence shows good agreement while the tribological equivalence is achievable using a reduced input torque.
\end{abstract}

\section{Keywords}

Hypoid gears; crossed helical gears; tribology; kinematics; flank velocity; Efficiency; back-to-back gear test.

\footnotetext{
* Corresponding author: Laboratory of Machine Elements and Machine Design, Department of Mechanical Engineering, Engineering Faculty, Aristotle University of Thessaloniki, 54124 Thessaloniki, Greece. email:amih@auth.gr

† 5-October 2015
} 


\section{Introduction}

Hypoid gears are commonly used in rear axle driven passenger cars and utility vehicles, as well as in most all-wheel drive vehicles and trucks. About $15 \%$ of the gear market is targeted at rear axle assemblies comprising spiral bevel or hypoid gear sets. An overall lower centre of mass has been a long recognized advantage, as well as fulfilling special cases where the axles should not intersect for mounting purposes. An additional feature is that by properly selecting the pinion spiral angle and the hypoid offset, the pinion shaft diameter can be increased which is beneficial since it is subjected to higher bending moments. The trade-off is between an increasing axial contact ratio and an increase in axial thrust. The main disadvantage of hypoid gears is the need for flank modifications, as well as being more susceptible to scuffing due to high loads and high sliding. Hypoid gearing is considered the most general gearing type whilst bevel, worm and even planar gearing can be considered as special subsets. Despite this, using the general hypoid gear theory does not lend itself directly to study the special subset cases. Litvin and Fuentes [1,2] presented a complete analysis of the design and manufacturing of hypoid gears. The main difficulty when considering the elastohydrodynamic (EHL) film calculation of hypoids is the complex geometry. Compared with helical and spur gears where meshing involves mostly planar geometric relations, the spatial meshing of hypoids is studied to a lesser extent. The meshing geometry is obtained in the studies by Karagiannis et al [3, 4] and Mohammadpour et al [5 - 7] using tooth contact analysis (TCA), and the CALYX software based on the work of Vijayakar [8]. Among other researchers, Simon has determined the load distribution using the finite element method (FEM) and the correct geometry. Instead of relying on the assumption of an ellipse in order to calculate the contact he used TCA and showed that in mismatched gears the ellipse is an unrealistic assumption [9, 10].

The analysis of crossed helical gears follows the meshing geometry. Each gear of the pair is a helical gear with well-defined flank geometry. The contact path of a crossed helical gear is a straight line. The geometric analysis is explained in depth by Grekoussis and Michailidis [11] using spatial geometry. The methodology described in [11] is used in the current study in order to explore the design space by calculating the rolling velocity direction relative to the contact ellipse, slide-roll ratio (SRR) and contact footprint ellipticity. A similar approach has been followed by Xu and Yang [12]. The absolute values of velocity and maximum Hertzian pressure can be adjusted independently by varying the input speed and torque. TCA has also been used by Zhang and Fang [13] for estimating the load carrying capacity and the load sharing factor between meshing teeth pairs of crossed helical gears. They showed that certain tooth profile modifications alter significantly the load sharing factor, resulting in only the middle portion of the tooth carrying the load. In the present study a properly designed tip relief correction is assumed, so that the load distribution is subject to smooth variation.

In order to consider two similar gears pairs from a tribological perspective, they should have a similar contact footprint ellipticity, pressures, rolling and sliding velocity and direction of lubricant entrainment, which is commonly assumed equal to the direction of sum velocity. The influence of lubricant entrainment direction was studied by Omasta et al [14], Hoehn et al [15] and Jalali-Vahid et al [16]. Its significance is in altering the lubricant film shape and side-leakage, thus the film thickness. Higher entrainment speed increases the asymmetry of the oil film provided that the oil entrainment angle with respect to the major axis of the Hertzian contact ellipse is the same.

In sections 2 and 3 of the present study a methodology is proposed to accurately calculate the sliding and sum velocities of a hypoid gear pair requiring only the basic input data according to ISO 23509 [17]. TCA results of the hypoid gear pair (maximum pressure, entrainment angle and contact radii) are used in conjunction with the velocity to estimate its tribological 
conditions using the film thickness and teeth friction coefficient (section 4). An extension of the method in section 5 allows the selection of a single experimental crossed helical gear pair that can be used in a closed power-loop test rig to simulate the original hypoid pair. Finally, in chapter 6 the torque and rotational velocity are subsequently adjusted following two alternative scenarios aiming at: (i) matching the maximum pressure and film thickness of the hypoid gear pair and (ii) matching the friction power loss.

\section{Crossed helical gears}

\subsection{Meshing}

When the helix angles on the pitch cylinders of two mating gears have the same magnitude but opposite directions, the axes of the gears are parallel and their planes of action coincide. If the helix angles of these two gears are different, then their axes are crossed, meaning that they are non-parallel and non-intersecting. Their planes of action are intersecting each other and the resulting intersection line is the path of contact (Figure 1). It is evident that it crosses normally both mating gear flanks at their contact point. When the pinion drives, the starting and end points of meshing are on the intersection of the path of contact with the tip cylinder of the wheel and pinion, respectively.

In helical gear pairs with parallel axes, the mating gear flanks contact each other along a common generating line, since their generating lines are parallel. These contact lines may extend along the entire face width or between a transverse surface and a tip cylinder. Consequently, helical gear pairs feature an overlap ratio in addition to the transverse contact ratio.

In crossed helical gear pairs the generating lines of the mating flanks are non-parallel. Therefore, the mating flanks contact each other at just one point that travels along the path of contact. There is no overlap ratio and crossed helical gear pairs feature only normal contact ratio.

Figure 1: Geometry of crossed helical gear pair. The path of contact is shown at the intersection of the two planes of action.

Considering a given pair of crossed helical gears, the normal pressure angle $\alpha_{\mathrm{n}}$, the pitch helix angles $\beta_{s 1,2}$ as well as the radii $r_{s 1,2}$ and $r_{\mathrm{a} 1,2}$ of the pitch and tip cylinders are assumed. The pinion is driving whereas the right-hand helix angles are defined as positive and the left-hand ones as negative.

The lengths of the approach $g_{a n 1}$ and recess $g_{a n 2}$ paths are given by the following equations:

$$
g_{a n 1,2}=\frac{r_{s 1,2}}{\cos \beta_{b 1,2}}\left(\sqrt{\left(\frac{r_{\mathrm{a} 1,2}}{r_{s 1,2}}\right)^{2}-\cos ^{2} \alpha_{t 1,2}}-\sin \alpha_{t 1,2}\right)
$$

A meshing point $Y$ can be defined by its radial distance $h_{1 Y}$ from the pitch cylinder. Its value is defined as positive for points on the addendum and negative for points on the dedendum. The following equations can be used to determine which point of the wheel flank comes in contact with a given arbitrary point of the pinion. 


$$
\begin{gathered}
f_{1 Y}=\left(1+\frac{h_{1 Y}}{r_{s 1}}\right)^{2} \\
\frac{g_{n Y}}{r_{s 1}}=\frac{1}{\cos \beta_{b 1}}\left(\sqrt{f_{1 Y}-\cos ^{2} \alpha_{t 1}}-\sin \alpha_{t 1}\right) \\
\frac{g_{n Y}}{r_{s 2}}=-\frac{1}{u} \frac{\cos \beta_{s 2}}{\cos \beta_{s 1}} \frac{g_{n Y}}{r_{s 1}} \\
f_{2 Y}=1+\frac{g_{n Y}}{r_{s 2}}\left(\frac{g_{n Y}}{r_{s 2}} \cos ^{2} \beta_{b 2}+2 \sin \alpha_{n}\right) \\
\frac{h_{2 Y}}{r_{s 2}}=\sqrt{f_{2 Y}}-1
\end{gathered}
$$

The geometrical data in the above equations are calculated as follows:

Transverse pressure angle $\alpha_{t}$

$$
\tan \alpha_{t 1,2}=\frac{\tan \alpha_{n 1,2}}{\cos \beta_{s 1,2}}
$$

Base helix angle $\beta_{b}$

$$
\tan \beta_{b 1,2}=\cos \alpha_{t 1,2} \tan \beta_{s 1,2}
$$

Gear ratio $u$

$$
u=\frac{r_{s 2}}{r_{s 1}} \frac{\cos \beta_{s 2}}{\cos \beta_{s 1}}
$$

\subsection{Kinematics}

According to ISO 1122-1:1998 [18], the pitch surface is the geometrical surface described by the instantaneous axis of relative movement of the mating gear, in relation to the gear under consideration. The pitch surfaces of cylindrical gear pairs with parallel axes are rolling without slipping. Pitch surfaces of gear pairs with crossed axes, such as crossed helical and hypoid gear pairs, are sliding along their tooth flanks.

The trajectory of a contact point on an active flank can be obtained by projecting the path of contact on a plane that tangents the flank at the contact point or, in other words, on the generating rack flank (Figure 2). The relative velocities of the pinion and gear flank at a given contact point along its trajectory, are respectively:

$$
\begin{gathered}
\frac{v_{f 1 Y}}{v_{1}}=\sqrt{f_{1 Y}-\left(\cos \alpha_{n} \cos \beta_{s 1}\right)^{2}} \\
\frac{v_{f 2 Y}}{v_{1}}=\frac{\cos \beta_{s 1}}{\cos \beta_{s 2}} \sqrt{f_{2 Y}-\left(\cos \alpha_{n} \cos \beta_{s 2}\right)^{2}}
\end{gathered}
$$




$$
\tan \gamma_{B E 1,2}=\frac{1}{\sin \beta_{b 1,2}} \sqrt{\frac{f_{1 Y}}{\cos ^{2} a_{t 1,2}}-1}
$$

where $\gamma_{B E 1,2}$, is the angle between the flank generating line and the trajectories.

It should be noted that the vector of the relative tangential velocity of the driving flank is directed towards the tooth root, whereas the vector of the driven flank is directed towards the tooth tip. The relative sliding velocity can be obtained by the vector difference of the above tangential velocities. The entrainment velocity is defined as half the sum velocity. In tribology the term "rolling” is interchangeably used with "entrainment" velocity

$$
\begin{aligned}
& \frac{\overrightarrow{v_{g Y}}}{v_{1}}=\frac{\overrightarrow{v_{f 1 Y}}}{v_{1}}-\frac{\overrightarrow{v_{f 2 Y}}}{v_{1}} \\
& \frac{\overrightarrow{v_{\Sigma Y}}}{v_{1}}=\frac{\overrightarrow{v_{f 1 Y}}}{v_{1}}+\frac{\overrightarrow{v_{f 2 Y}}}{v_{1}}
\end{aligned}
$$

Figure 2: Flank velocities projected at contact point $\mathrm{Y}$. The trajectories of the contact points are shown as dotted lines on the flanks of the pinion and the wheel. The sliding and sum velocities are calculated using vector analysis.

\subsection{Contact footprint and pressure}

As outlined previously, the mating flanks of a crossed helical gear pair contact each other at a point. In order to calculate the contact footprint and pressure, the Hertzian theory can be applied. The flanks are modelled in the vicinity of the contact point as two cylinders with generating lines coincidental to the flank generating ones. Their radii $\rho_{B 1,2}$ and crossing angle $\varphi \varphi$ can be calculated as follows:

$$
\begin{gathered}
\rho_{B 1,2 Y}=\frac{r_{s 1,2}}{\cos \beta_{b 1}} \sqrt{f_{1,2 Y}-\cos ^{2} \alpha_{t 1,2}} \\
\varphi=\beta_{t 1}+\beta_{t 2} \\
\sin \beta_{t 1,2}=\tan \alpha_{n} \tan \beta_{b 1,2}
\end{gathered}
$$

According to Hertzian theory, the shape of the resulting footprint is elliptical. The major $a_{Y}$ and minor $b_{Y}$ semi-diameters of the contact ellipse are calculated as follows:

$$
\begin{aligned}
& a_{Y}=w_{Y} \xi_{Y} \\
& b_{Y}=w_{Y} \eta_{Y}
\end{aligned}
$$




$$
\begin{gathered}
w_{Y}=\sqrt[3]{\frac{1.5 F_{n Y}\left(k_{1}+k_{2}\right)}{\frac{1}{\rho_{B 1 Y}}+\frac{1}{\rho_{B 2 Y}}}} \\
\text { where } k_{1,2}=\frac{1-v_{1,2}^{2}}{E_{1,2}}
\end{gathered}
$$

Parameters $\xi_{Y}$ and $\eta_{Y}$ can be numerically determined as functions of the auxiliary angle $\theta_{Y}$, which depends only on the radii of curvature and crossing angle $\varphi$ of the modelled cylinders:

$$
\begin{gathered}
\cos \theta_{Y}=\sqrt{1-\frac{4 \lambda_{Y}}{\left(1+\lambda_{Y}\right)^{2}} \sin ^{2} \varphi} \\
\text { where } \lambda_{Y}=\frac{\rho_{B 1 Y}}{\rho_{B 2 Y}}=\frac{r_{s 1}}{r_{s 2}} \frac{\cos \beta_{b 2}}{\cos \beta_{b 1}} \frac{\sqrt{f_{1 Y}-\cos ^{2} \alpha_{t 1}}}{\sqrt{f_{2 Y}-\cos ^{2} \alpha_{t 2}}}
\end{gathered}
$$

Details on the computation of $\xi_{Y}$ and $\eta_{Y}$ can be found in Appendix A. The direction of the contact ellipse at a meshing point $Y$ is defined by the angle $\varphi^{\prime}{ }_{Y}$ between its major axis and the pinion flank generating line passing through that point [19]:

$$
\cos 2 \varphi_{Y}^{\prime}=\frac{\lambda_{Y}+\cos 2 \varphi}{\sqrt{1+\lambda_{Y}^{2}+2 \lambda_{Y} \cos 2 \varphi}}
$$

It should be noted that the direction of the contact ellipse varies throughout the meshing cycle, because it depends on the curvature ratio, although the crossing angle of the flank generating lines remains unchanged. Finally, the maximum Hertzian $\sigma_{H Y}$ pressure is:

$$
\sigma_{H Y}=1.5 \frac{F_{n Y}}{\pi a_{Y} b_{Y}}
$$

where $F_{n Y}$ is the normal force at contact point $\mathrm{Y}$.

\section{Hypoid gear pairs}

\subsection{Meshing}

As their name implies, the geometrically exact pitch surfaces of a hypoid gear pair are two hyperboloids contacting each other along a common generating line. The current Gleason manufacturing technology generates gears with pitch surfaces that closely approximate the hyperboloids by a conical frustum. Therefore, the generating lines of the mating flanks are crossing each other, even at a small angle. Moreover, several limitations regarding the face width, minimum number of teeth, spiral and pressure angles are imposed.

Following the application of properly designed flank modifications (such as crowning), the contact elongated elliptical footprint can be extended across the flank approximating a line. 
Elastic deformations of gears, shafts etc. strongly affect the flank contact conditions. In other words, the actual flank surfaces and the deformations should be taken into account to accurately determine the actual meshing. As a first approximation, if manufacturing deviations, applied modifications and elastic deformations are neglected, the path of contact of a hypoid gear pair is a line normal to the mating flanks.

Considering a given pair of hypoid gears, the normal pressure angle of the active flanks $\alpha_{n}$, the spiral angles $\beta_{m 1,2}$, the pitch angles $\delta_{1,2}$, the mean pitch diameters $d_{m 1,2}$ (or radii $r_{m 1,2}$ ) and the mean addenda $h_{a m 1,2}$ are assumed as known. The lengths of approach $g_{a n 1}$ and recess $g_{a n 2}$ paths are given by the following:

$$
\begin{gathered}
g_{a n 1,2}=r_{n 1,2}\left[\sqrt{\left(1+\frac{h_{a m 1,2}}{r_{n 1,2}}\right)^{2}-\cos ^{2} \alpha_{n}}-\sin \alpha_{n}\right] \\
\text { where } r_{n 1,2}=\frac{r_{m 1,2}}{\cos ^{2} \beta_{m 1,2} \cos \delta_{1,2}}
\end{gathered}
$$

The above equations are obtained by simulating the meshing of the given hypoid gear pair with a crossed helical one, having helix angles equal to the spiral angles, and equal pressure angle and addendums. For convenience this gear pair will be referred hereafter as "mean crossed helical”.

\subsection{Kinematics}

The mean crossed helical gear pair can be employed to calculate the sliding and sum velocities of an arbitrary contact point using the equations given in section 2 . However, it should be noted that this approximation is accurate only at the mean point of the hypoid gears. In order to calculate the velocities at other points, one has to consider the tooth curvature on the crown gear face and determine the trajectory of the contact point.

Face hobbed gears without flank modifications are considered in the current study. With face hobbing, the curve along the length of the tooth is an extended epicycloid and is a function of the relative roll between the work piece and the cutter. At an arbitrary mesh point Y given by radius $r_{Y 1,2}$, the spiral angle $\beta_{Y 1,2}$ can be calculated using the cutter radius $r_{c 01,2}$, the roll circle radius $E_{b 1,2}$ and the base circle radius $E_{y 1,2}$ using the following equations:

$$
\begin{gathered}
\tan \beta_{Y 1,2}=\frac{R_{Y 1,2}-\left(E_{x 1,2}-E_{b 1,2}\right) \cos \psi_{Y 1,2}}{\left(E_{x 1,2}-E_{b 1,2}\right) \sin \psi_{Y 1,2}} \\
\text { where } E_{x 1,2}=E_{y 1,2}+E_{b 1,2} \\
R_{Y 1,2}=\frac{r_{Y 1,2}}{\sin \delta_{1,2}} \\
\text { and } \cos \psi_{Y 1,2}=\frac{R_{Y 1,2}^{2}+E_{x 1,2}-r_{c 01,2}}{2 E_{x 1,2} r_{Y 1,2}}
\end{gathered}
$$


Having determined the spiral angles at a mesh point $\mathrm{Y}$ for both pinion and wheel, it is possible to define an infinitesimal narrow crossed helical gear pair that simulates the kinematic conditions of the hypoid gears at that considered point. It will be referred to as "running simulating crossed helical gear pair". The pitch helix angles $\beta_{s 1,2}$ and pitch radii $r_{s 1,2}$ are calculated as follows:

$$
\begin{gathered}
\beta_{s 1,2}=\beta_{Y 1,2} \\
r_{s 1,2}=\frac{r_{Y 1,2}}{\cos \delta_{1,2}}
\end{gathered}
$$

It is evident, that when $\mathrm{Y}$ is the mean point of the hypoid gear pair, the running and mean simulating crossed helical gear pairs coincide. At the mean point of the hypoid gear pair, the sliding and sum velocities are calculated at the pitch cylinders i.e. $h_{Y 1}=0$, of the mean simulating gear pair using the equations given in the previous chapter.

The next meshing point is defined considering the trajectory of the contact point on the flank of the generating gear of the wheel and pinion, respectively. If in the next instant, the contact point moves towards a new position at $\Delta y$ from the generating gear mid-plane, it also covers a distance $\Delta \mathrm{x}$ along the length of the pinion or wheel flank:

$$
\Delta x=\frac{\Delta y}{\tan \gamma_{F 1,2}}
$$

$\Delta y$ is considered as positive when the new position of the contact point is on the addendum. At the new position, the spiral angles $\beta_{Y^{\prime} 1,2}$ can be obtained by equation (28) substituting its cone distance $R_{Y^{\prime} 1,2}$ as calculated per the procedure outlined in Appendix B. Alternatively, the following equation can be used, which assumes that the curve along the length of the tooth is approximately a circular arc [20]:

$$
R_{Y^{\prime} 1,2}=\sqrt{R_{m 1,2}^{2}+2 R_{m 1,2} \Delta_{x} \cos \beta_{m 1,2}+\Delta_{x}^{2}}
$$

The mean cone distance $R_{m 1,2}$ is calculated by equation (30) for $r_{Y 1,2}=r_{m 1,2}$. The pitch radii of the running simulating crossed helical gear pair are obtained from the following equation:

$$
r_{S Y^{\prime} 1,2}=R_{Y^{\prime} 1,2} \sin \delta_{1,2}
$$

The radial distance $h_{Y^{\prime} 1}$ of the new position $Y^{\prime}$ of the contact point from the pitch cylinder of the helical pinion is:

$$
\begin{gathered}
\frac{h_{1 Y^{\prime}}}{r_{s Y^{\prime} 1}}=\sqrt{\left(\frac{g_{n Y}}{r_{s Y^{\prime} 1}}+\sin \alpha_{n}\right)^{2}+\cos ^{2} \alpha_{n}-1} \\
g_{n Y}=\frac{\Delta y}{\cos \alpha_{n}}
\end{gathered}
$$


Having defined the running simulating crossed helical gear pair $\left(\beta_{S 1,2}=\beta_{Y^{\prime} 1,2}\right.$ and $r_{s 1,2}=$ $\left.r_{s Y^{\prime} 1,2}\right)$ the relative sliding and sum velocities at the new contact point $Y^{\prime}\left(h_{1 Y}=h_{1 Y^{\prime}}\right)$ are obtained as presented in section 2.2.

\subsection{Contact footprint and pressure}

The particulars outlined in section 3.1 indicate that tooth contact analysis (TCA) is the most appropriate method to calculate the teeth contact footprint. This method meshes the surfaces of the gears and attempts to numerically resolve the contact points under load by solving the stiffness matrix using Finite Element Analysis. The gear surfaces are generated by a given set of inputs regarding the manufacturing method, such as cutter geometry, machine settings and blank dimensions.

Among the advantages of using TCA is the ability to solve the contact problem under static or quasi-static mode. Manufacturing deviations, misalignments and deformation due to loading can be taken into account and the load distribution of each tooth during the meshing cycle is calculated. The results obtained by TCA include besides loads, the approach of the surfaces termed as ease-off both under unloaded and loaded conditions. The calculated distances are then used as a guideline in order to define the flank crowning needed in order to obtain a better contact footprint.

\section{Tribological conditions}

\subsection{Film thickness and friction power loss}

In order to evaluate the film thickness of the elliptical point contact with angled lubricant flow the equation given by Chittenden et al. [21] is used. The equations refer to an ellipsoid having principal major axis radius $\mathrm{R}^{\prime}$ and minor axis $R "$. The lubricant is assumed to entrain at an angle to the minor axis $R^{\prime \prime}$. An equivalent second ellipsoid is calculated with radii $\mathrm{R}_{\mathrm{e}}$ in the entrainment direction and $R_{S}$ in the transverse or else side leakage direction. Assuming fully flooded lubricated contacts, friction is due to shearing of the lubricant. Gear contacts are typically highly loaded; so, the lubricant behaviour is in the visco-elastic lubrication regime. The contacting bodies are assumed to be smooth. In the present study, no starvation of reverse flow is considered but using the methodology presented by Mohammadpour et al[22] the results can be extended.

$$
\begin{gathered}
h_{c o}^{*}=4.31 U^{*^{0.68}} G^{*^{0.49}} W^{*^{-0.073}}\left(1-e^{-1.23\left(\frac{R_{S}}{R_{e}}\right)^{\frac{2}{3}}}\right) \\
W^{*}=\frac{\pi W_{j}}{2 E_{r} R_{e}^{2}}, U^{*}=\frac{\pi \eta_{0} U}{4 E_{r} R_{e}}, G^{*}=\frac{2}{\pi}\left(E_{r} \alpha\right), h_{c o}{ }^{*}=\frac{h_{c o}}{R_{e}} \\
E_{r}=\frac{\pi}{k_{1}+k_{2}}
\end{gathered}
$$

In section 3 the radii of the contacting cylindrical bodies $\rho_{B y 1,2}$ are calculated along with the crossing angle, $\varphi$. Using equations (42) - (44) the equivalent ellipsoid is calculated [23]: 


$$
R^{\prime}=\frac{1}{2 A}, R^{\prime \prime}=\frac{1}{2 B}
$$

Where the auxiliary values $A$ and $B$ can be found by solving the following system:

$$
\begin{gathered}
B-A=\frac{1}{2}\left(\frac{1}{\rho_{B y 1}^{2}}+\frac{1}{\rho_{B y 2}^{2}}+\frac{2 \cos 2 \varphi}{\rho_{B y 1} \rho_{B y 2}}\right)^{\frac{1}{2}} \\
A+B=\frac{1}{2}\left(\frac{1}{\rho_{B y 1}}+\frac{1}{\rho_{B y 2}}\right)
\end{gathered}
$$

The second equivalent ellipsoid that is aligned to the entrainment direction is calculated as follows:

$$
\frac{1}{R_{e}}=\frac{\cos ^{2} \varepsilon_{\xi \Sigma Y}}{R^{\prime \prime}}+\frac{\sin ^{2} \varepsilon_{\xi \Sigma Y}}{R^{\prime}}, \frac{1}{R_{S}}=\frac{\sin ^{2} \varepsilon_{\xi \Sigma Y}}{R^{\prime \prime}}+\frac{\cos ^{2} \varepsilon_{\xi \Sigma Y}}{R^{\prime}}
$$

The friction coefficient for the lubricated contact is given by Johnson and Greenwood [24] as:

$$
\begin{gathered}
\mu=0.87 \alpha \tau_{0}+\frac{1.74 \tau_{0}}{\sigma_{H Y} / 1.5} \ln \left(\left(\frac{1.2}{\tau_{0} h_{c o}}\right)\left(\frac{2 \dot{K} \eta_{0}}{1+9.6 \zeta}\right)^{\frac{1}{2}}\right) \\
\zeta=\frac{4}{\pi}\left(\frac{\dot{K}}{\frac{h_{c o}}{R^{\prime \prime}}}\right)\left(\frac{\sigma_{H Y} / 1.5}{E^{\prime} R^{\prime \prime} K^{\prime} \rho^{\prime} c^{\prime} U}\right)^{\frac{1}{2}} \\
E^{\prime}=\frac{E_{r}}{\pi}
\end{gathered}
$$

\section{Calculation of crossed helical gear pair data for testing}

Evaluating the scuffing resistance of hypoid gear sets has been always a main concern. The typical setup for testing is even nowadays a closed power-loop test rig with two hypoid gear sets on one end and a spur gear pair on the other. Such test rigs have limitations and high associated costs [25]. Hypoid gear pairs may exhibit different efficiency when used back-toback in a closed power-loop test rig since one pair is being driven on the coast side and the other on the drive side. Furthermore, matching contact patterns in two gear sets is rather impossible, since the gears are always run-in before operation and therefore no two pairs are identical. The use of a 5-axis CNC machine is recently introduced as a potential manufacturing method to improve the gear pair matching but most pairs are still produced by elaborate gear generators using face hobbing or milling. The equivalent crossed helical gears of ISO 23509 [17] can be used for calculating the kinematic conditions only at the mean point. Since this modelling approach results in gear pairs with very large ratios and non- 
integer number of teeth, it cannot be applied to design crossed helical gears for fitting in a specific test rig. In the present study, the parameters of the test rig installed in the lab of Machine Elements and Machine Design (L.M.E.M.D.) are used as an example. It has a centre distance of $112.8 \mathrm{~mm}$ and can accommodate crossed axes helical gear pairs with shaft angles between $15-20^{\circ}$. The applied torque load is defined manually using a lever and weights allowing the relevant rotation of two flanges which are once rotated bolted together. The achievable loading is between 50-500 Nm. In order to define the experimental gear pair, the parameters listed in Table 1 must be calculated.

Table 1 Crossed helical gear pair data

\begin{tabular}{|l|c|c|}
\hline Normal pressure angle & \multicolumn{1}{|l|}{} & $\alpha_{n}$ \\
\hline Number of teeth of gear 1 & - & $z_{1}$ \\
\hline Number of teeth of gear 2 & - & $z_{2}$ \\
\hline Module & $m m$ & $m_{n}$ \\
\hline Helix angle base circle gear 1 & $\circ$ & $\beta_{1}$ \\
\hline Helix angle base circle gear 2 & $\circ$ & $\beta_{2}$ \\
\hline $\begin{array}{l}\text { Addendum modification } \\
\text { coefficient (profile shift) gear 1 }\end{array}$ & - & $x_{1}$ \\
\hline $\begin{array}{l}\text { Addendum modification } \\
\text { coefficient (profile shift) gear 2 }\end{array}$ & - & $x_{2}$ \\
\hline Addendum correction of gear 1 & - & $k_{1}$ \\
\hline Addendum correction of gear 2 & - & $k_{2}$ \\
\hline
\end{tabular}

The equivalent gear pair must maintain the helix angles of the original hypoid pair, as well as the module and normal pressure angle. The former is necessary to be as close as possible to the real pair since it strongly affects the overall tooth dimensions.

The rolling and sliding velocities are calculated as described previously. A proposed starting point is to maintain the number of teeth of the bigger gear, and select the smaller gear so that the module is close to the original. An additional limitation is that the typical helical gear hobs are available in specific modules, so the gear module should be approximated to the closest available. Once close enough, a minor adjustment of the helix angles will be necessary so that the module is correct, alternatively an addendum modification (profile shift) can be calculated. For a non-zero total addendum modification (V-gears) of the gear pair the working helix angles and the shaft angle are different than the original values and an iterative process is required for the actual addendum modified working angles to match the original reference helix angles.

A methodology has been implemented for calculating the remaining unknown parameters (number of teeth and addendum modification) for a given centre distance. Any gear pair ratio that satisfies the angle constraints mentioned, will have the same ratio of sliding and rolling velocity at the pitch point as the mean face-width of the hypoid pair, but will deviate significantly at the dedendum and addendum.

The helix angles are then calculated and through an iterative method they are matched to the hypoid gear pair. A MATLAB code is built by L.M.E.M.D. to provide a systematic calculation of all possible combinations of input parameters for the screw gears and compare the resulting angles of lubricant entrainment, $S R R$ and ellipticity ratio with those of the given hypoid pair.

\section{Results and discussion}




\subsection{Hypoid gear pair}

According to ISO 23509:2006 - Method 1 (Gleason) the variables included in Table 2 are required. The ISO method does not account for any special modifications, nor does it take into account any special cutter shape.

Table 2 Input hypoid parameters

\begin{tabular}{|l|c|l|l|c|l|}
\hline Parameter name & Symbol & Value & Parameter name & Symbol & Value \\
\hline Shaft angle & $\Sigma$ & $90^{\circ}$ & Number of teeth pinion & $z_{1}$ & 13 \\
\hline Hypoid offset & $a$ & $24 \mathrm{~mm}$ & Number of teeth wheel & $z_{2}$ & 36 \\
\hline Pressure angle & $a_{m n}$ & $20^{\circ}$ & Mean spiral angle pinion & $\beta_{m 1}$ & $45^{\circ} 59^{\prime}$ \\
\hline Normal module & $m_{m n}$ & $\begin{array}{l}3.3842 \\
\mathrm{~mm}\end{array}$ & Face width tooth wheel & $b_{2}$ & $30 \mathrm{~mm}$ \\
\hline Gear ratio & $i$ & 2.769 & $\begin{array}{l}\text { Outer pitch diameter } \\
\text { wheel }\end{array}$ & $d_{e 2}$ & $165 \mathrm{~mm}$ \\
\hline $\begin{array}{l}\text { Addendum modification } \\
\text { coef. }\end{array}$ & $\begin{array}{l}x_{h m 1} \\
=-x_{h m 2}\end{array}$ & 0 & Blade groups & $z_{0}$ & 11 \\
\hline $\begin{array}{l}\text { Basic crown gear } \\
\text { addendum factor }\end{array}$ & $k_{h a p}$ & 1 & Cutter radius & $r_{c 0}$ & $63.5 \mathrm{~mm}$ \\
\hline $\begin{array}{l}\text { Basic crown gear } \\
\text { dedendum factor }\end{array}$ & $k_{h f p}$ & 1.25 & $\begin{array}{l}\text { Thickness modification } \\
\text { coefficient }\end{array}$ & $x_{s m n}$ & 0 \\
\hline Addendum angle of wheel & $\theta_{a 2}$ & $1.5^{\circ}$ & Pinion speed & $n_{1}$ & 4500 rpm \\
\hline Dedendum angle of wheel & $\theta_{f 2}$ & $-1.5^{\circ}$ & Sense of pinion & & Right \\
\hline Driving member & & Pinion & Driving flank & & Concave \\
\hline \begin{tabular}{l} 
Wheel cutting method \\
\hline
\end{tabular} & Formate & Cutting method & $\begin{array}{l}\text { Face } \\
\text { Hobbing }\end{array}$ \\
\hline
\end{tabular}

The parameters in Table 3, are required for calculating the sliding and sum (rolling) velocities and are obtained following the ISO 23509:2006 calculation.

Table 3 Calculated hypoid parameters

\begin{tabular}{|l|c|c|c|}
\hline Parameter name & Symbol & Pinion & Wheel \\
\hline Mean diameter & $d_{0 m}$ & $63.32 \mathrm{~mm}$ & $137.47 \mathrm{~mm}$ \\
\hline Mean Spiral Angle wheel & $\beta_{m 2}$ & See table 2 & $27^{\circ} 36^{\prime}$ \\
\hline Pitch angle & $\delta$ & $29^{\circ} 10^{\prime}$ & $59^{\circ} 32^{\prime}$ \\
\hline Face width tooth & $b$ & $33.78 \mathrm{~mm}$ & See table 2 \\
\hline Addendum & $h_{k m}$ & $3.3845 \mathrm{~mm}$ & $3.3845 \mathrm{~mm}$ \\
\hline Dedendum & $h_{f m}$ & $4.06 \mathrm{~mm}$ & $4.06 \mathrm{~mm}$ \\
\hline Outer pitch cone distance & $R_{e}$ & $82.8397 \mathrm{~mm}$ & $95.7169 \mathrm{~mm}$ \\
\hline Crown gear to cutter centre distance (base circle) & $\rho_{P 0}=E_{x}$ & $65.2705 \mathrm{~mm}$ & $92.4075 \mathrm{~mm}$ \\
\hline Epicycloid roll circle radius & $\rho_{P 0}-\rho_{b}=E_{b}$ & $19.0589 \mathrm{~mm}$ & $19.2636 \mathrm{~mm}$ \\
\hline
\end{tabular}

In Figure 3, the 3D model - as created by the TCA software - is shown side by side to a 2D sketch of the hypoid gear pair. The hypoid offset is positive and the angle of the pinion is greater than that of the wheel. The tooth height is approximately equal along the entire tooth width. 
Figure 3: A) 3D model of the hypoid pair used in TCA. B) Sketch of the main diameters and mean pitch cones.

Figure 4, displays the ease-off of the pinion flank as calculated by TCA. It is apparent that the contact occupies a limited area and is indeed a point contact.

Figure 4: Ease-off pinion flank. The plane is divided to the number of nodes used by TCA.

In order to calculate the power loss, the required friction coefficient is computed according to equation (46). The parameters of typical lubricant and material (case hardened steel) of the contacting surfaces are given in Table 4.

Table 4 Lubricant and contacting surface properties

\begin{tabular}{|l|c|c|c|}
\hline Lubricant atmospheric dynamic viscosity at $40^{\circ} \mathrm{C}$ & $\mathrm{Pa} . \mathrm{s}$ & $\eta_{0}$ & 0.195 \\
\hline $\begin{array}{l}\text { Lubricant atmospheric dynamic viscosity at } \\
100^{\circ} \mathrm{C}\end{array}$ & $\mathrm{Pa} . \mathrm{s}$ & $\eta_{0}$ & 0.0171 \\
\hline Pressure viscosity coefficient & $\mathrm{Pa}^{-1}$ & $\alpha$ & $2.383 \times 10^{-8}$ \\
\hline Lubricant Eyring shear stress & $\mathrm{MPa}$ & $\tau_{0}$ & 2 \\
\hline Density of contacting solids & $\mathrm{kg} / \mathrm{m} 3$ & $\rho^{\prime}$ & 7850 \\
\hline Heat capacity of contacting solids & $\mathrm{J} / \mathrm{kgK}$ & $c^{\prime}$ & 470 \\
\hline Thermal conductivity of contacting solids & $\mathrm{W} / \mathrm{mK}$ & $K^{\prime}$ & 46 \\
\hline Thermal conductivity of lubricant & $\mathrm{W} / \mathrm{mK}$ & $\dot{K}$ & 0.14 \\
\hline Heat capacity of lubricant & $\mathrm{J} / \mathrm{kgK}$ & $c$ & 2000 \\
\hline
\end{tabular}

\subsection{Sliding and rolling velocity}

The calculation methodology presented in section 3, is compared using the gear pair data shown in tables 1 and 2, to other available methodologies. ISO TR13989-2 [26] includes a method to calculate the velocities at the mean point only. It is based on a single virtual crossed gear pair. The TCA software uses 3D vector estimation of the velocities. Finally, Klein [27] calculates the velocity of the hypoid gear pair by substituting it with a pair of virtual spur gears and modifies the corresponding equations in order to include the sliding velocity at the pitch point. The relative sliding velocities are presented along the contact path in Figure 5, while the relative sum velocities in Figure 6.

Figure 5: Comparison of the relative sliding velocity.

The sum velocity plotted in Figure 6 is compared against the results obtained according to Klein. TCA does not provide values for the sum velocity. The ISO $13989-2$ provides a calculation of the sum velocity only at the pitch point of the virtual crossed gear pair which corresponds to the mid-face width point of the hypoid gears.

Figure 6: Comparison of the sum velocity 
Although all methods provide similar results, some key observations can be made. Regarding sliding velocity, TCA shows some noise issues due to difficulty in accurately obtaining the centre of the contact, as well as due to surface discretization. However, TCA takes into account all aspects such as deformations and tooth forms and is well accepted in literature. The ISO method overestimates the sliding in the dedendum similarly to the spur virtual gear method used by Klein. The proposed method using the running crossed helical gear pair follows closely an undeformed and geometrically exact hypoid pair. The sum velocity in the pitch point is equal in all three methods. In the addendum the match is very close between the proposed method and that of Klein, but an observable difference is evident in the dedendum.

\subsection{Experimental crossed gear pair}

The method presented in section 5 allows for the identification of an equivalent gear pair suitable for tests. The results are shown in Table 5.

Table 5 Equivalent gear pair data

\begin{tabular}{|l|l|c|l|l|l|}
\hline & & & Gear 1 (pinion) & & Gear 2 \\
\hline Axes angle & $\left(^{\circ}\right)$ & $\Sigma$ & $18^{\circ} 24^{\prime}$ & & \\
\hline Centre-distance & $(\mathrm{mm})$ & $\mathrm{a}$ & 112.8 & & \\
\hline Normal module & $(\mathrm{mm})$ & $m_{n}$ & 3.25 & & \\
\hline Number of teeth & - & $z_{1}$ & 21 & $z_{2}$ & 35 \\
\hline $\begin{array}{l}\text { Helix angle at } \\
\text { reference circle }\end{array}$ & $\left(^{\circ}\right)$ & $\beta_{1}$ & $-45^{\circ} 39^{\prime}$ & $\beta_{2}$ & $27^{\circ} 15^{\prime}$ \\
\hline $\begin{array}{l}\text { Addendum } \\
\text { modification } \\
\text { coefficient }\end{array}$ & $x_{1}$ & 0 & $x_{2}$ & 0 \\
\hline Pressure angle & $\left(^{\circ}\right)$ & $\alpha_{n}$ & 20 & $d_{b 2}$ & 118.4191 \\
\hline Base diameter & $(\mathrm{mm})$ & $d_{b 1}$ & 86.6047 & $d_{w 2}$ & 127.9592 \\
\hline Working diameter & $(\mathrm{mm})$ & $d_{w 1}$ & 97.6408 & $a_{w t 2}$ & $22^{\circ} 15^{\prime} 52^{\prime \prime}$ \\
\hline $\begin{array}{l}\text { Transverse working } \\
\text { angle }\end{array}$ & $\left(^{\circ}\right)$ & $a_{w t 1}$ & $27^{\circ} 30^{\prime} 16^{\prime} ”$ & & 20 \\
\hline
\end{tabular}

The following figures (Figure 7 and Figure 8) show a comparison of the velocities between the hypoid gear pair and the equivalent crossed helical one. The sliding velocity has an almost ideal match. It is apparent that for the sum velocity a slight difference in the shape is present, but the maximum and minimum values in the addendum and dedendum are adequately similar.

Figure 7: Relative sum velocity comparison

Figure 8: Relative sliding velocity comparison

\subsection{Experimental conditions}


The equivalent crossed helical gear pair closely resembles the hypoid in aspects of velocity and geometry. However, an important difference should be emphasized caused by the geometry of the contacting flanks. The concave-convex form of the hypoid teeth increases the maximum transferrable power for a given allowable maximum surface pressure.

When choosing experimental conditions, it is obvious that a compromise is necessary and it can be driven by a different goal. In this study, two different scenarios are evaluated and presented as shown in Table 6. The first aims at having the same friction coefficient - hence the values of the pressure and velocity are set equal to those of the hypoid gear pair; whereas in the second scenario the absolute value of the power loss is of importance with as close as possible values of the maximum pressure. The reader can of course use the methodology to design a different scenario with other goals (such as friction power intensity, flash temperature etc.). The rotational speed is selected to match the linear velocity of the pinion at the mean face width point $\mathrm{v}_{1}$ :

$$
v_{1}=\omega_{1} r_{m 1}=\omega_{s 1} r_{s 1}
$$

Table 6 Experimental conditions

\begin{tabular}{|l|l|l|l|}
\hline & Hypoid Pair & \multicolumn{2}{|c|}{ Crossed helical pair } \\
\hline Speed (rpm) & 4500 & 3000 & 3000 \\
\hline Torque (Nm) & 101.088 & 40 & 60 \\
\hline
\end{tabular}




\subsection{Hertz contact footprint}

In Figures 9, 10 the size of the Hertz contact footprint is shown for both scenarios for the crossed helical gear pair. For comparison in Figure 11 the contact footprint of the hypoid gear pair is shown. The horizontal axis represents the contact path. The vectors of the sum and sliding velocity are also shown.

Figure 9: Hertz contact footprint of the crossed helical gear pair at $60 \mathrm{Nm}$.

Figure 10: Hertz contact footprint of the crossed helical gear pair at $40 \mathrm{Nm}$.

Figure 11: Hertz contact footprint of the hypoid gear pair at $101.3 \mathrm{Nm}$.

\subsection{Maximum pressure}

The assumed load distribution percentage is shown in Figure 12. In Figure 13 the maximum pressure is shown for all scenarios. The hypoid gear pair has a smoother easing in and out of the load and a continuous curve since it is calculated taking into account the deformations.

Figure 12: Load distribution along the contact path for the crossed helical gear pair.

Figure 13: Maximum pressure along the contact path for all cases.

\subsection{Friction coefficient and central film thickness}

Figure 14 shows the central film thickness as calculated along the contact path for the crossed helical gear pair and the hypoid one. It can be observed that the film thickness (for the two load cases of 40 and $60 \mathrm{Nm}$ ) is only marginally affected by the increase in pressure. The film thickness value ranges between 2.5-3 $\mu$ m that appears higher than typical EHL film thickness values. Using a thermal EHL solver should provide more accurate results.

Figure 14: Central film thickness

Figure 15 shows the friction values along the contact path. Experimental values for reference are difficult to obtain. However, the average friction coefficient is close to the model of Wech 
[28] for hypoid gears, the AGMA technical paper of Xu et al. [29] and the newer works of Mohammadpour et al. [22,30]. The friction model is only valid for the visco-elastic regime. In this paper, meshing cycle regions with pressures below $200 \mathrm{MPa}$ and high speed fell in the iso-viscous rigid regime and thus are excluded. The calculations of the lubrication regime has been done using the Gv and Ge parameters of Hamrock and Dowson [31] The number of such points is small and the power loss related is marginal.

Figure 15: Friction coefficient along the contact path

\subsection{Efficiency and power loss}

Table 7 shows a summary of the results obtained from the tribology calculations. The power loss is calculated using the normal force and the average values of the friction, sliding velocity:

$$
\eta=1-\frac{P_{v}}{P_{i}}=1-\frac{\bar{\mu} F_{n} \bar{V}_{g}}{P_{i}}
$$

Figure 16 and Figure 17 show the power loss and efficiency comparisons.

Table 7 Summary

\begin{tabular}{|l|l|l|l|}
\hline Summary & Hypoid Pair [30] & \multicolumn{2}{|l|}{ Crossed helical pair } \\
\hline Speed (rpm) & 4500 & 3000 & 3000 \\
\hline Torque (Nm) & 101.088 & 40 & 60 \\
\hline Input power [kW] & 47.636 & 12.566 & 18.85 \\
\hline Normal force [kN] & 2.123 & 1.247 & 1.870 \\
\hline Average friction coef. $(\mu)[-]$ & 0.0204 & 0.0204 & 0.0232 \\
\hline Average sliding velocity [m/s] & 5.64 & 5.78 & 5.78 \\
\hline Maximum pressure [GPa] & 0.736 & 0.734 & 0.864 \\
\hline Power loss [W] & 244 & 147 & 250.89 \\
\hline Efficiency & $99.49 \%$ & $98.83 \%$ & $98.67 \%$ \\
\hline
\end{tabular}

Figure 16: Power loss comparison

Figure 17: Power efficiency comparison

\section{Conclusions}


Hypoid gear pairs are commonly used in vehicles of all types especially in rear axles. Their complex geometry, which is closely related to the specific manufacturing process, and the high cost render tribological tests exorbitantly complex and costly. For rating purposes equivalent helical crossed axes gear pairs can be used.

The current study initially presents a kinematic analysis of hypoid gears based on crossed helical gear pairs defined for each contact point. Additionally, the study explores the use of a single crossed helical gear pair that is tribologically equivalent to a given hypoid gear pair. Utilizing results for pressure and entrainment angle obtained by TCA for the hypoid pair, the contact parameters are studied in order to calculate the tribological conditions that need to be matched. The torque and rotational velocity are selected to match the maximum pressure and film thickness of the hypoid gear pair. Two scenarios are examined since in many occasions the experiments may aim to simulate not just a similar contact but rather an equal power loss rate.

Using a friction model that takes into account a Ree-Eyring non-Newtonian lubricant, the friction coefficient is calculated, which shows that the friction is in good agreement between the crossed helical gear pairs and the hypoid one.

A theoretical correspondence between hypoid and crossed helical gears is examined and proven using the software tools presented in the current study and test scenarios. Experiments with crossed helical gears in back-to-back test rigs can be designed to research hypoid gears reducing the cost. The method approximates sufficiently the tribology making it suitable for comparative testing of lubricants or efficiency. 


\section{References:}

[1] Litvin, F.L. and Fuentes, A. “Gear geometry and applied theory”, 2nd ed., New York: Cambridge University Press, 2004.

[2] Litvin, F.L., Fuentes, A., Fan, Q. et al., “Computerized design, simulation of meshing, and contact and stress analysis of face-milled formate generated spiral bevel gears”. Mech. Mach. Theory, 2002, 37, pp. 441-459.

[3] Karagiannis, I., Theodossiades, S. and Rahnejat, H., "On the dynamics of lubricated hypoid gears”, Mech. Mach. Theory, 2012, 48, pp. 94-120.

[4] Karagiannis, I., Theodossiades, S., An alternative formulation of the dynamic transmission error to study the oscillations of automotive hypoid gears, Journal of Vibration and Acoustics 136 (1), 011001

[5] Mohammadpour, M., Theodossiades, S. and Rahnejat, H., Multiphysics investigations on the dynamics of differential hypoid gears, Journal of Vibration and Acoustics 136 (4), 041007

[6] Mohammadpour, M., Theodossiades, S. and Rahnejat, H., "Elastohydrodynamic lubrication of hypoid gears at high loads”, Proc. IMechE, Part J: J. Engineering Tribology, 2012, 226(3), pp. 183-198.

[7] Mohammadpour, M., Theodossiades, S., Rahnejat, H. and Kelly, P., “Transmission efficiency and noise, vibration and harshness refinement of differential hypoid gear pairs”, Proc. IMechE, Part K: J. Multi-body Dynamics, 2014, 228(1), pp. 19-33.

[8] Vijayakar, S., “Tooth Contact Analysis Software: CALYX, Advanced Numerical Solutions”, Hilliard, OH, 1998.

[9] Simon, V., “Load distribution in hypoid gears”, J. Mech. Des., 1998, 122, pp. 529-535.

[10] Simon, V., “FEM stress analysis in hypoid gears”, Mech. Mach. Theory, 2000, 35, pp. 1197-1220.

[11] Grekoussis R. and Michailidis Th. Rechnergestutzte Auslegung von StirnSchraubradgetrieben, antriebstechnik, 1983, 22:2, 41-44.

[12] Xu, L. and Yang, C., "Elastohydrodynamic lubrication calculation and measure for crossed helical gears”, Proc. IMechE, Part J: J Engineering Tribology, 2006, 220, pp. 499-505.

[13] Zhang, Y. and Fang, Z., “Analysis of tooth contact and load distribution of helical gears with crossed axes”, Mech. and Mach. Theory, 1999, 34, pp. 41-57. 
[14] Omasta, M., Křupka, I. and Hartl M., "Effect of surface velocity directions on elastohydro-dynamic film shape”, Trib. Trans, 2013, 56(2), pp. 301-309.

[15] Hoehn, B.-R., Michaelis, K., Mayer, J. and Weigl, A., "Influence of surface velocity directions on lubricant film formation in EHL point contacts”, Trib. Int, 2012, 47, pp. 9-15.

[16] Jalali-Vahid, D., Rahnejat, H., Gohar, R. and Jin, Z.M., "Prediction of oil-film thickness and shape in elliptical point contacts under combined rolling and sliding motion”, Proc. IMechE, Part J: J. Engineering Tribology, 2000, 214(5), pp. 427-437.

[17] ISO, “ISO 23509, Bevel and hypoid gear geometry”, 2006.

[18] ISO, "ISO 1122-1, Vocabulary of gear terms -- Part 1: Definitions related to geometry”, 1998

[19] Grekoussis, R. and Michailidis, Th., "Stellung der Hertzschen Druckellipse auf der Oberfläche zweier einander in einem Punkt berührender Körper „, Konstruktion, 1980, 32, pp. 303-306.

[20] Grekoussis, R., "Vergleichende Untersuchungen zur Fresstragfähigkeit von Hypoid und Stirnrädern", Diss, Technischen Hochschule München. 1969.

[21] Chittenden, R. J., Dowson, D., Dunn, J. F., Taylor, C. M., “A theoretical analysis of the isothermal elastohydrodynamic lubrication of concentrated contacts. II. General case, with lubricant entrainment along either principal axis of the hertzian contact ellipse or at some intermediate angle”, Proc. R. Soc. Lond. A.: Math., Phys. Eng. Sci., 1985, 397, pp. 271-294.

[22] Mohammadpour, M., S. Theodossiades, and H. Rahnejat, "Transient mixed nonNewtonian thermo-elastohydrodynamics of vehicle differential hypoid gears with starved partial counter-flow inlet boundary." Proc. IMechE, Part J: Journal of Engineering Tribology, 2014, 228, pp. 1159-1173.

[23] Bhusan, B., "Modern Tribology Handbook- 3.2.3 Contact of Two Cylinders with Inclined Axes”, Volume 1, 2000, pp. 149-151.

[24] Johnson, K.L., Greenwood, J.A., “Thermal analysis of an Eyring fluid in elastohydrodynamic traction”, Wear, 1980, pp. 353-374.

[25] Langenbeck, K. Benthake, H., "Verspannungs-Getriebeprüfstände für Forschung und Entwicklung”, VDI-Z 1973, pp. 115-121.

[26] ISO/TR 13989-2 Calculation of scuffing load capacity of cylindrical, bevel and hypoid gears - Part 2: Integral temperature method”, 2000. 
[27] Klein M.M., “Zur Fresstragfähigkeit von Kegelrad- und Hypoidgetrieben”, Diss, , Technischen Hochschule München, 2012

[28] Wech, L.: Untersuchungen zum Wirkungsgrad von Kegelrad- und Hypoidgetrieben, Diss. TU München, 1987.

[29] Xu H, Kahraman A, Houser DR (2005) A model to predict friction losses of hypoid gears. AGMA Tech. Pap.: 05FTM06

[30] Mohammadpour, M., Theodossiades, S., Rahnejat, H., Saunders, T., "Non-Newtonian mixed elastohydrodynamics of differential hypoid gears at high loads”, 2014, Meccanica 49, pp. 1115-1138.

[31] Hamrock, B. J., Dowson, D. "Ball bearing lubrication - the elastohydrodynamics of elliptical contacts”, Wiley-Interscience, New York, 1981

[32] Abramowitz, M., and I. A. Stegun. "Handbook of Mathematical Functions. Dover Publications”, 1965.

[33] Grekoussis, R. and Michailidis, Th., "Näherungsgleichungen zur Nach- und Entwurfsrechnung der Punktberührung nach Hertz”, Konstruktion, 1981, 33, pp. 135139. 


\section{Appendix A}

The calculation of parameters $\xi$ and $\eta$ when the auxiliary angle $\theta$ is known, can be carried out numerically as outlined below. At first, the following equation is solved numerically for $\varepsilon$ :

$$
\cos \theta=\frac{E(\varepsilon)\left(1+\cos ^{2} \varepsilon\right)-2 K(\varepsilon) \cos ^{2} \varepsilon}{E(\varepsilon) \sin ^{2} \varepsilon}
$$

Then, the complete elliptic integrals of the first $K(\varepsilon)$ and second $E(\varepsilon)$ kind with modulus $\varepsilon$ must be calculated. They can be computed very efficiently using the arithmetic-geometric mean, [32]. Finally, the parameters $\xi$ and $\eta$ are calculated using the following relationships:

$$
\begin{gathered}
\xi=\sqrt[3]{\frac{K(\varepsilon)-E(\varepsilon)}{\frac{\pi}{4} \sin ^{2} \varepsilon(1-\cos \theta)}} \\
\eta=\sqrt[3]{\frac{E(\varepsilon) \cos \varepsilon-K(\varepsilon) \cos ^{3} \varepsilon}{\frac{\pi}{4} \sin ^{2} \varepsilon(1+\cos \vartheta)}}
\end{gathered}
$$

Alternatively, the approximate equations introduced by Grekoussis/Michailidis [33] can be used. 


\section{Appendix B}

Figure 18 shows the calculation method of the cone distance using the extended epicycloid kinematics and the main parameters involved.

The parametric equations of an extended epicycloid in a coordinate system (x,y) are:

$$
\begin{gathered}
x_{1,2}=\left(E_{b 1,2}+E_{x 1,2}\right) \cos \varphi_{\text {epic }}+r_{0 c 1,2} \cos \left(\varphi_{\text {epic }}+\beta_{\text {epic } 1,2}\right) \\
y_{1,2}=\left(E_{b 1,2}+E_{x 1,2}\right) \sin \varphi_{\text {epic }}+r_{0 c 1,2} \sin \left(\varphi_{\text {epic }}+\beta_{\text {epic } 1,2}\right) \\
\text { where } \beta_{\text {epic } 1,2}=\frac{E_{x 1,2}}{E_{b 1,2}} \varphi_{\text {epic }}
\end{gathered}
$$

$\varphi_{\text {epic }}$ is the angle of the rolling circle centre from the $\mathrm{x}$ axis and is the independent parameter of the epicycloid curve.

$\beta_{\text {epic } 1,2}$ is the local rotation angle of the rolling circle and therefore it is equal to the diameter ratio of the base and roll circles.

The above function is symmetrical and in the range $[0, \pi]$ and for any given radius point a specific angle $\varphi$ is assigned. Hence, a unique Cartesian coordinate pair can be found for each curve point. Provided that $\Delta \mathrm{x}$ is adequately small, it can be assumed that the distance of two successive points on the curve, is equal to the cord length. Given the cone distance $R_{m 1,2}$, the coordinates $\left(x_{m 1,2}, y_{m 1,2}\right)$ of the mean point of the hypoid pair can be found. Then, the coordinates of the next meshing point $\mathrm{Y}^{\prime}$ are found numerically by solving the following equation. By applying eq. B.4 two possible solutions can be found with $\varphi_{\text {epic }}$ greater or less than the initial angle. The selection is made depending if we are heading toward the addendum or dedendum of the gear. The addendum of the pinion is heading towards greater angles $\varphi_{\text {epic }}$.

$$
\sqrt{\left(x_{m 1,2}-x_{Y^{\prime} 1,2}\right)^{2}+\left(y_{m 1,2}-y_{Y^{\prime} 1,2}\right)^{2}}=\Delta x
$$

Finally, the cone distance $\mathrm{R}_{\mathrm{Y}^{\prime} 1,2}$ can be calculated:

$$
R_{Y^{\prime} 1,2}=\sqrt{x_{Y^{\prime} 1,2}^{2}+y_{Y^{\prime} 1,2}^{2}}
$$

Figure 18: Calculation of the cone distance at point $Y^{\prime}$ 
Nomeclature:

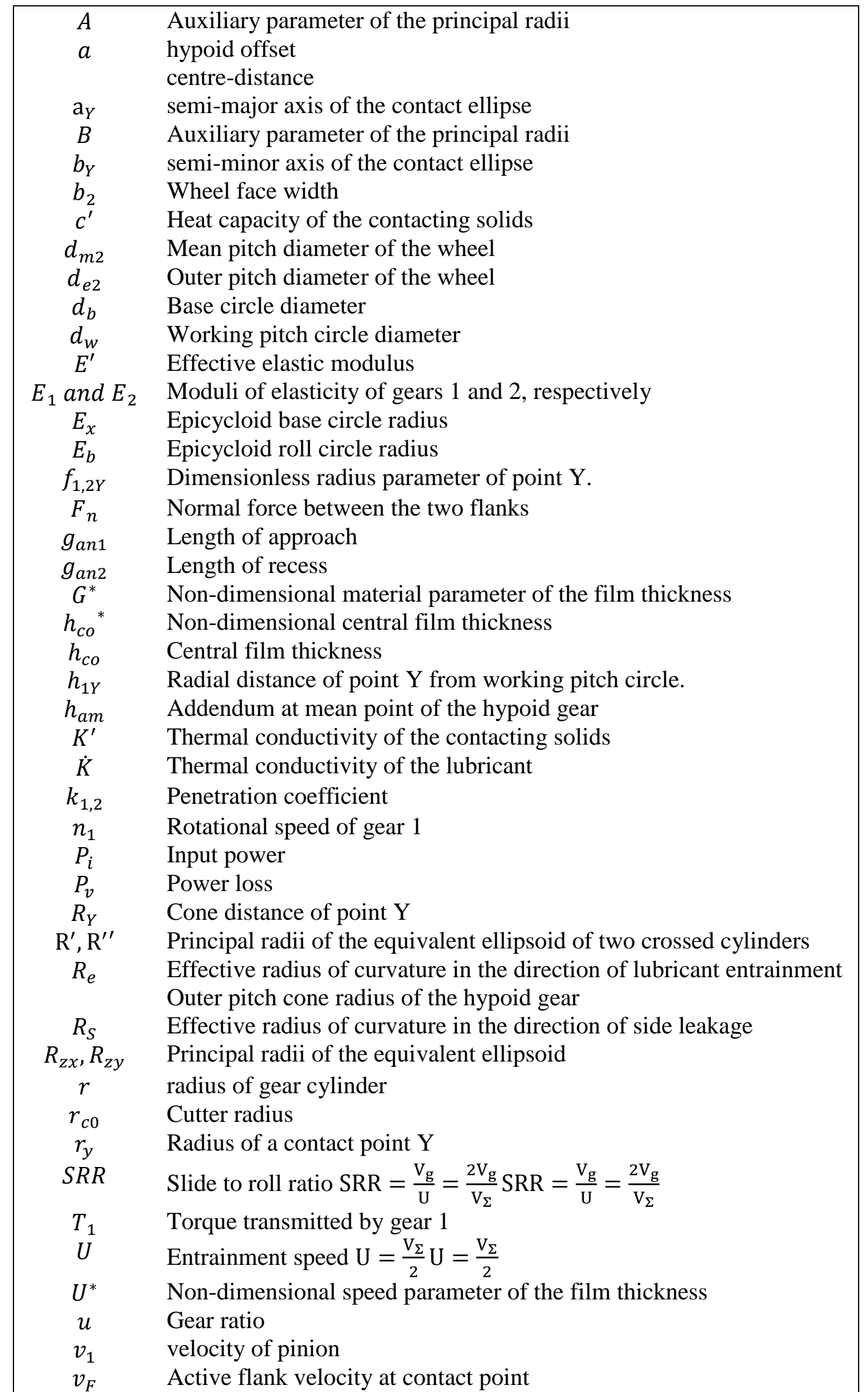




\begin{tabular}{|cl|}
$v_{g}$ & Sliding velocity \\
$\bar{V}_{g}$ & Mean sliding velocity \\
$W^{*}$ & Non-dimensional load parameter of the film thickness \\
$W_{j}$ & Normal load at each contact point \\
$w_{Y}$ & Load factor \\
$z_{0}$ & Number of blade groups (only face hobbing) \\
$z_{1,2}$ & Tooth number of gear 1 or 2 \\
\hline
\end{tabular}

Greek symbols

\begin{tabular}{|cl|}
\hline$\alpha_{n}, \alpha_{t}$ & Pressure angle (normal and transverse plane) \\
$\alpha$ & Viscosity-pressure coefficient \\
$\beta$ & Helix angle \\
$\beta_{m 1,2}$ & Mean spiral angle of hypoid pinion (1) and wheel (2) \\
$\gamma_{B}$ & angle between the trajectory of contact point on the flank and the \\
$\delta$ & generator line \\
$\Delta x$ & Pitch angle of the hypoid cone \\
$\Delta y$ & Tooth distance along the length of the pinion or wheel flank \\
& plane \\
$\varepsilon$ & Auxiliary angle of elliptical integral \\
$E(\varepsilon)$ & First kind complete elliptical integral \\
$\zeta$ & Thermal ratio for heat viscosity reduction of oil \\
$\eta_{Y}$ & Auxiliary elliptical parameter \\
$\eta$ & Efficiency \\
$\eta_{0}$ & Lubricant atmospheric dynamic viscosity \\
$\theta$ & Auxiliary angle \\
$K(\varepsilon)$ & Second kind complete elliptical integral \\
$\lambda_{y}$ & Ratio of radii of curvature \\
$\mu$ & Friction coefficient \\
$\bar{\mu}$ & Mean friction coefficient along the contact path \\
$v_{1} a n d v_{2}$ & Poisson's ratio of gears 1 and 2, respectively \\
$\xi_{Y}$ & Auxiliary elliptical parameter \\
$\rho^{\prime}$ & Density of contacting solids \\
$\rho_{P 0}$ & Crown gear to cutter centre distance \\
$\rho_{B y}$ & Curvature radius at a contact point y \\
$\sigma_{H 0}$ & Surface pressure \\
$\Sigma$ & Shaft angle \\
$\tau_{0}$ & Eyring shear stress \\
$\varphi$ & Crossing angle of cylindrical contact bodies \\
$\varphi_{y}^{\prime}$ & Angle between the major ellipse angle and the principal curvature \\
$\psi_{Y 1,2}$ & plane of gear flank 1 \\
& Auxiliary epicycloid angle \\
&
\end{tabular}

Subscripts

\begin{tabular}{|cl|}
\hline 1,2 & Gear 1 and 2 \\
\hline $\mathrm{a}$ & tip circle of gear cylinder \\
$b$ & Base circle
\end{tabular}


$n \quad$ Normal plane

$m \quad$ Mean point

$s \quad$ Pitch circle of crossed helical gears

$t \quad$ Transverse plane

$Y \quad$ Any point of mesh along the contact path of crossed helical gears 